\title{
Management of Inherited von Willebrand Disease in Italy: Results from the Retrospective Study on 1234 Patients
}

\author{
Augusto B. Federici, M.D., 1,2 Paolo Bucciarelli, M.D. ${ }^{2}$ Giancarlo Castaman, M.D., ${ }^{3}$ \\ Luciano Baronciani, Ph.D.,' 2 Maria T. Canciani, Ph.D., 2 Maria G. Mazzucconi, M.D., 4 \\ Massimo Morfini, M.D., 5 Ángiola Rocino, M.D., ${ }^{\circ}$ Mario Schiavoni, M.D., 7 \\ Emily Oliovecchio, Ph.D., ${ }^{8}$ Alfonso lorio, M.D., 8 and Pier M. Mannucci, M.D. ${ }^{9}$
}

Von Willebrand disease (VWD) is the most common inherited bleeding disorder and is due to quantitative and/or qualitative defects of von Willebrand factor (VWF). Despite the improved knowledge of the disease, detailed data on VWD types requiring specific treatments have not been reported thus far. To determine the number and types of VWD requiring therapy with desmopressin (DDAVP) and/or VWF/FVIII concentrates in Italy, a national registry on VWD (RENAWI) was organized. Only 16 of 48 centers included VWD in the RENAWI with diagnoses performed locally. Patients with uncertain results were retested by two expert laboratories using multimeric analysis and mutations of the VWF gene. A total of 1234 of 1529 (81\%) cases satisfied the inclusion criteria and could be classified as VWD1 (63\%), VWD2A (7\%), VWD2B (6\%), VWD2M (18\%), VWD2N (1\%), and VWD3 (5\%). VWD types were also confirmed by DNA analyses and occur in young adults (83\%), mainly in women (58\%). Mucosal bleedings (32 to $57 \%$ ) are more frequent than hematomas $(13 \%)$ or hemarthrosis $(6 \%)$. Most patients were exposed to an infusion trial with desmopressin (DDAVP) and found responsive with the following rates: VWD1 (69\%), VWD2A (26\%), VWD2M (29\%), and VWD2N (71\%). However, DDAVP was not always used to manage bleeding in all responsive patients and VWF/FVIII concentrates were given instead of or together with DDAVP in VWD1 (30\%), VWD2A (84\%), VWD2B (62\%), VWD2M (63\%), VWD2N (30\%), and VWD3 (91\%). Data of the RENAWI showed that correct VWD identification and classification might be difficult in many Italian centers. Therefore, evidence-based studies should be organized only in well-characterized patients tested by laboratories that are expert in the clinical, laboratory, and molecular markers of VWD.

\footnotetext{
${ }^{1}$ Division of Hematology and Transfusion Medicine, L. SACCO University Hospital and Department of Internal Medicine, University of Milan, Milan, Italy; ${ }^{2} \mathrm{~A}$. Bianchi BONOMI Hemophilia and Thrombosis Center, IRCCS Cà Granda Foundation, Policlinico Hospital, Milan, Italy; ${ }^{3}$ Division of Hematology, San BORTOLO Hospital, Vicenza, Italy; ${ }^{4}$ Hemophilia Center, Department of Hematology, University of Rome, Rome, Italy; ${ }^{5}$ Hemophilia Center, CAREGGI Hospital, Florence, Italy; ${ }^{6}$ Hemophilia Center, PELLEGRINI Hospital, Naples, Italy; ${ }^{7}$ Hemophilia Thrombosis Center, POLICLINICO Hospital, Bari, Italy; ${ }^{8}$ Hemophilia Center, University of Perugia, Perugia, Italy; ${ }^{9}$ Scientific Direction IRCCS Ca GRANDA Foundation Maggiore Policlinico Hospital, Milan, Italy.

Address for correspondence and reprint requests: Augusto B.
}

Federici, M.D., Division of Hematology and Transfusion Medicine, Department of Internal Medicine, University of Milan, L. SACCO University Hospital, Via G. B. Grassi, 76 - 20154 Milan, Italy (e-mail: augusto.federici@unimi.it).

Von Willebrand Disease: Local Diagnosis and Management of a Globally Distributed Bleeding Disorder; Guest Editor, Emmanuel J. Favaloro, Ph.D., F.F.Sc. (RCPA).

Semin Thromb Hemost 2011;37:511-521. Copyright (C) 2011 by Thieme Medical Publishers, Inc., 333 Seventh Avenue, New York, NY 10001, USA. Tel: +1(212) 584-4662. DOI: http://dx.doi.org/10.1055/s-0031-1281037. ISSN 0094-6176. 
KEYWORDS: von Willebrand disease, mucosal bleeding, von Willebrand factor assays, clinical, laboratory and molecular markers, desmopressin, VWF/FVIII concentrates

von Willebrand disease (VWD) is the most common inherited bleeding disorder. It is very heterogeneous, and correct diagnosis and treatment may sometimes be difficult. ${ }^{1,2}$ Despite improved knowledge on the management of VWD as described in several guidelines prepared by panels of experts on the field,,$^{3-7}$ no detailed data on the cases requiring specific treatments have been available thus far. The results of several epidemiological studies suggested that VWD could be extremely frequent in certain geographic areas. ${ }^{8}$ The most recent European and Canadian studies investigating the clinical and molecular markers for diagnosis and management of VWD1 could indeed improve the knowledge of the disease but could not explore the clinical use of specific therapeutic agents. ${ }^{9,10}$

A retrospective registry on VWD, called the Registro nazionale dei pazienti con malattia di Willebrand, or the National Registry of von Willebrand Disease (RENAWI), was organized in Italy in 2002. Aims of this registry were to evaluate the natural history of VWD in Italy in a large cohort of patients $(>1000)$ and, more specifically, to obtain actual data on number of VWD types requiring treatment with desmopressin (DDAVP) and of VWF/factor (F)VIII concentrates. Since the last largest report on 100 Italian VWD patients collected from four major Italian Hemophilia Centers was published in $1977,{ }^{11}$ the RENAWI might describe indeed the natural history of VWD in Italy, after the first introduction of DDAVP in clinical practice. $^{12}$

\section{PATIENTS AND METHODS}

\section{Design of the Study}

In Italy, the Italian Association of Hemophilia Centers (AICE) has been organizing a general registry on hemophilia since late 1980s, but data collected until late 1990s were mainly devoted to bloodborne infections observed especially in patients with hemophilia. Clinical and laboratory parameters on VWD have been collected since 2002 from 48 Hemophilia Centers, and general data on VWD have been published within the registry on Hemophilia and Allied Disorders. ${ }^{13}$ In the case of VWD patients, the Italian Ministry of Health supported a specific registry to collect detailed information about VWD types requiring the use of therapeutic agents such as DDAVP and/or VWF/FVIII concentrates. Table 1 shows the different phases of the studies, the number of participating centers, and patients enrolled in these two registries.

Data of RENAWI were collected from January 2002 throughout December 2005. Investigators of each participating center received a computerized program and were trained to include VWD patients into the database. Among many other parameters, information was collected on (1) VWD types with age and sex distribution, (2) type of bleeding episodes, (3) identification of VWD cases responsive to DDAVP, and (4) number of patients treated with DDAVP only and/or those with VWF/FVIII concentrates. A total of 16 of 48 centers (33\%) could enroll patients into RENAWI. Patients were defined by specific codes to ensure anonymity. In the case of more patients from the same family, the family group was also indicated. The first enrollment was closed on December 2005, but the participating centers were requested to complete their data thereafter, and additional information was accepted by the coordinator until December 2006. During the first analysis of data, among the 1529 total patients, $>400$ cases did not meet the criteria for a correct

Table 1 Italian Centers and Patients Included in RENAWI versus Those Reported Annually in the Registry on Hemophilia and Allied Disorders of the AICE (Update December 2010)

Retrospective Registry (RENAWI: 2002-2006) versus Data of AICE General Registry (2010)

No. of participating Hemophilia Centers $=16-48$

Patients enrolled in the registry in January $2005=1529-2420$

Patients not included in the registry $=295$ not applicable

- Included by more than one center $=35$ verified

-Did not meet criteria for VWD diagnosis $=246$ analyses not tested

- Lost at follow-up or died $=14$ verified

-Classification of total VWD included $=1234-2420$

VWD1 $=779(63 \%)-1773(73 \%)^{*}$

$\mathrm{VWD} 2 \mathrm{~A}=87(7 \%)-208(9 \%)$

$\mathrm{VWD} 2 \mathrm{~B}=73(6 \%)-113(5 \%)$

$\mathrm{WWD} 2 \mathrm{M}=219(18 \%)-164(6 \%) *$

VWD2N $=10(1 \%)-40(2 \%)$

VWD3 $=66(5 \%)-122(5 \%)$

*Note that the frequency of VWD1 and VWD2M observed in the RENAWI is relatively lower and higher (respectively) than that of the AICE general registry. This is mainly due to the more sensitive ELISA-VWF:RCo and multimeric analyses used in the RENAWI allowing a better identification of VWD2M versus previously diagnosed VWD1 according to fewer tests.

RENAWI, National Registry of von Willebrand Disease; AICE, Italian Association of Hemophilia Centers; VWD, von Willebrand disease. 
diagnosis of VWD. The Hemophilia Centers were thus requested to provide additional information together with plasma samples and DNA sent for additional laboratory investigations. Despite additional data, 275 cases remained excluded because of registration in more than one center $(n=35)$, incomplete or incorrect diagnosis $(n=226)$, lost at follow-up, or died $(n=14)$. Eventually, in 2007, 1234 cases were available for the second analysis, and these could be also tested for $V W F$ molecular defects during the last 3 years (Table 1 ).

\section{Ethical Issues, Blood Collection, and Laboratory Methods}

Patients were informed about the anonymous use of their data as well as the purpose of the study and gave their informed consent. The study was performed according to the Declaration of Helsinki and was approved by the Ethical Committee of the 16 centers involved in RENAWI. Venous blood was obtained at each center during regular screening at the time of diagnosis and at the time of follow-up visits. Plasma samples were obtained and kept frozen at $-40^{\circ} \mathrm{C}$ by the Hemophilia Centers. Bleeding time (BT) was measured by the Simplate-II R (Organon Teknica Corp., Durham, NC, USA), FVIII by one-stage coagulometric assay, VWF:antigen (Ag) by commercial kits, and homemade enzyme-linked immunosorbent assay (ELISA) using polyclonal antibodies against $\mathrm{VWF}^{2,3} \mathrm{VWF}$ :ristocetin cofactor $(\mathrm{RCo})$ was measured by aggregometry using formalin-fixed platelets from normal donors; when plasma VWF:RCo was $<15 \mathrm{U} / \mathrm{dL}$, VWD patients were investigated using the more sensitive ELISAVWF:RCo assay. ${ }^{14}$ Ristocetin-induced platelet agglutination (RIPA) was performed in platelet-rich plasma by aggregometry, and changes in light transmission were inscribed in a potentiometric chart recorder. RIPA values were expressed in terms of the minimal concentration of ristocetin giving at least a $30 \%$ increase in transmission (the normal range was 0.8 to $1.2 \mathrm{mg} / \mathrm{mL}$ ristocetin). ${ }^{2,3}$ VWF multimeric pattern was evaluated in patients' plasma by low-resolution gel electrophoresis. ${ }^{2,3}$ For molecular diagnosis, genomic DNA was extracted from peripheral blood using standard methods. Oligonucleotides used in this study and detailed procedures are available on request. Polymerase chain reaction was performed to amplify the whole $V W F$ gene coding region of the propositus, and sequence analysis was performed as previously reported. ${ }^{15}$

\section{Criteria for Diagnosis of Von Willebrand Disease Types}

Unfortunately, at the time of the first design of RENAWI, the detailed questionnaire later tested in
VWD1 and used to calculate the bleeding score (BS) was not available; ${ }^{16}$ therefore, data on BS could not be reported in the RENAWI. Patients were included in the RENAWI if they fulfilled all the criteria recommended by the Scientific Standardization Committee, subcommittee on VWF of the International Society on Thrombosis \& Haemostasis (ISTH), translated into a diagnostic flowchart in its updated version. ${ }^{3,17}$ Fig. 1 summarizes the criteria used to classify VWD patients.

Diagnosis of VWD1 was the most critical and was based on the VWF:RCo (upper normal limit for non-O blood group $=60 \mathrm{U} / \mathrm{dL}$ ) and VWF:Ag plasma levels (upper normal limit for non-O blood group $=68$ $\mathrm{U} / \mathrm{dL}$ ) and a complete set of multimers in plasma in at least one member of the same family. According to the definition of VWD1, characterized by reduced levels of normal VWF, VWF:RCo and VWF:Ag values were equally reduced with a VWF:RCo/Ag ratio $>0.6$. This value represents the lower limit of the VWF:RCo/Ag values recently obtained in 1200 normal individuals used as a control in the European project Molecular and Clinical Markers on Diagnosis and Management of type 1 VWD. ${ }^{9}$ VWD1 patients showed all three of the criteria (bleeding history, familial bleeding history, and lower VWF:RCo levels) recently discussed. ${ }^{5}$

Participating hematologists were requested to review their diagnosis several times by repeating assays at their local laboratories; in most cases the final diagnosis was eventually also confirmed by the coordinating center by using multimeric analysis and mutations of the $V W F$ gene. DNA was available in all affected members of VWD2A, VWD2B, VWD2M, VWD2N and in most VWD3 (82\%) and VWD1 (60\%). Most identified mutations had been previously recorded in the ISTH VWF database (www.vwf.group.shef.ac.uk; accessed on December 27, 2010). The typical localization of molecular defects within the entire VWF gene defects is reported in Fig. 2.

\section{Infusion Trial with DDAVP and Clinical Use of DDAVP and/or VWF/FVIII Concentrates}

Information about the infusion trial with DDAVP and the clinical use of DDAVP and/or VWF/FVIII concentrates were also included in RENAWI. An infusion trial with DDAVP was recommended in at least one member of the families with VWD1, VWD2A, VWD2M, and VWD2N (Fig. 1). To test the biological response, blood was collected to measure VWF/FVIII activities before and 1 and 2 hours postinfusion: Patients were considered responsive to DDAVP according to recently published criteria. ${ }^{18,19}$

Only three concentrates containing VWF are currently licensed in Italy for VWD patients: Alphanate 


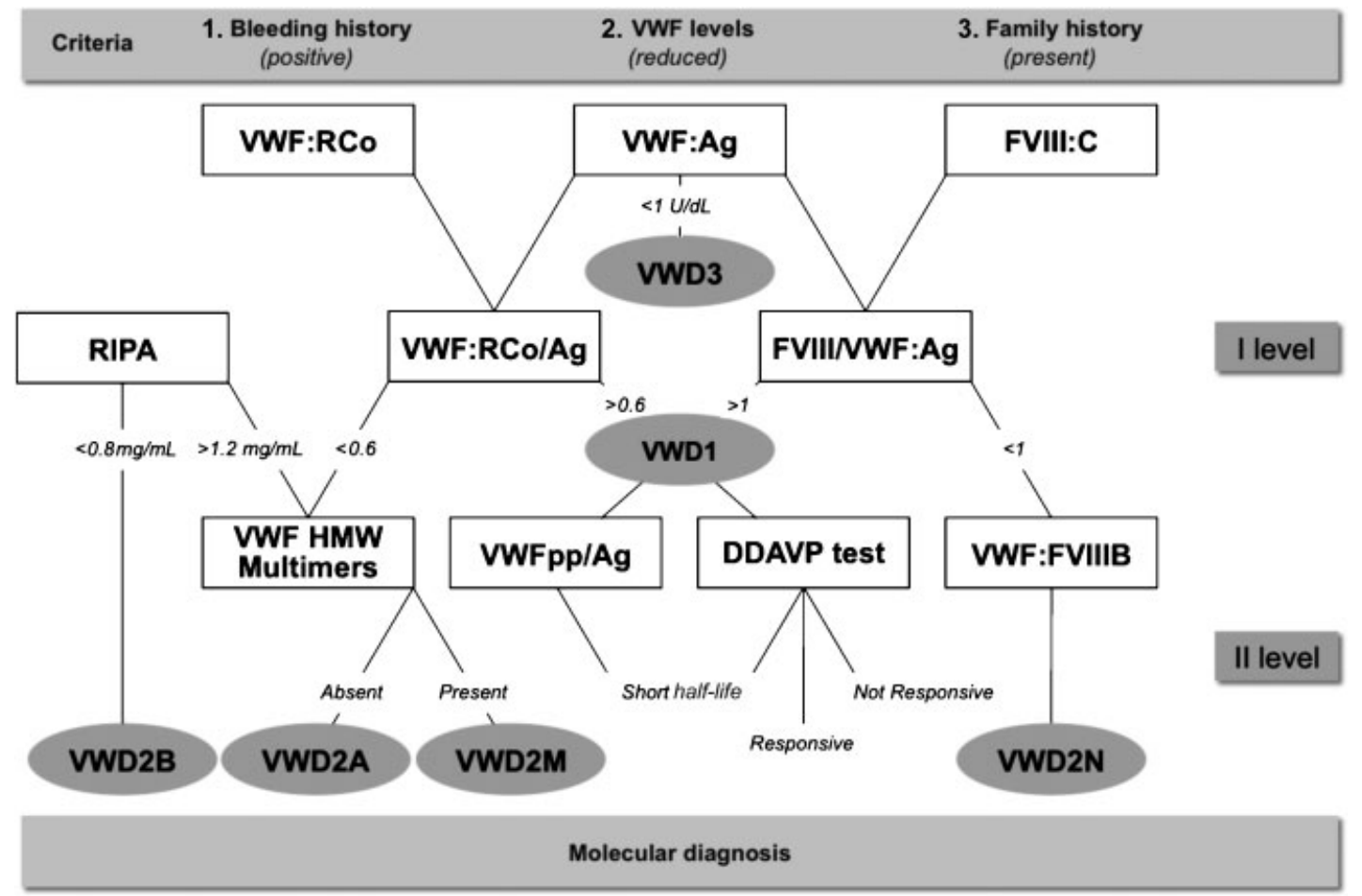

Figure 1 Flowchart proposed for the correct diagnosis and classification of different von Willebrand disease (VWD) types, partially modified from those reported previously. ${ }^{3,17}$ Once bleeding history of the suspected patients with VWD is collected and family history of bleeding investigated, a reduced level of von Willebrand factor (VWF) should be measured by using WWF:ristocetin cofactor (RCo). Level I of diagnosis: WWD3 can be diagnosed in case of undetectable VWF:antigen (Ag). Factor (F) VIII is always reduced in VWD3 and in VWD2N: It can be reduced or normal in all the other VWD types. VWD2B can be identified with heightened ristocetin-induced platelet agglutination (RIPA) $(<0.8 \mathrm{mg} / \mathrm{mL})$, whereas VWD1, VWD2A, and VWD2M are characterized by low RIPA (>1.2 mg/mL). A proportionate reduction of both VWF:Ag and VWF:RCo with a WWF:RCo/Ag ratio $>0.6$ suggests WWD1. If the VWF:RCo/Ag ratio is $<0.6$, WWD2A, VWD2B, or VWD2M should be suspected. WWD2N can be suspected in the case of FVIII:VWF ratio $<1$. A FVIII:VWF ratio $>1$ is usually associated with VWD1. Level II of diagnosis: Multimeric analysis in plasma is necessary to distinguish between VWD2A (lack of the largest and intermediate multimers) and VWD2M (all the multimers present). WWF propeptide (pp)-to-VWF:Ag is increased in VWD1 with a short half-life of VWF. Desmopressin (DDAVP) infusion test can identify patients with no biological response or a short biological response to this drug. WWF:FVIIIB should be performed to confirm VWD2N. Once phenotypic diagnosis is performed, mutations should be searched for (molecular diagnosis) to confirm VWF defects within the family of VWD patients (Fig. 2). HMW, high molecular weight; FVIII:C, factor VIII coagulant activity.

(Grifols), Fahndi (Grifols), and Haemate-P (CSLBehring). These concentrates contain both VWF and FVIII and can therefore be defined as VWF/FVIII concentrates. They were recommended for VWD therapy because they were also assessed for their efficacy and safety in Italian patients with VWD. ${ }^{20-22}$

\section{Statistical Analysis}

Continuous variables were expressed as mean plus or minus standard deviation or median and range. Comparison between continuous variables was made by the Student $t$ test, Mann-Whitney $U$ test, or one-way analysis of variance, where appropriate. All statistical analysis was performed using the SPSS software package (version 15.0; SPSS, Chicago, IL, USA).

\section{RESULTS}

\section{Demographic, Clinical, and Laboratory Data of the Von Willebrand Disease Cohort}

The data obtained by RENAWI have been collected using a specific database in only a third of the Italian centers currently participating in the general registry on hemophilia and allied bleeding disorders of the AICE. ${ }^{13}$ Indeed, these 16 of 48 centers in the past 10 years have been following the majority of the Italian VWD population, that is, 1529 of 2420 cases (63\%) (Table 1). Because only these 1234 patients have been centrally reevaluated for VWD diagnosis, we decided to describe the current management of VWD in Italy by using only data from this well-characterized cohort of patients. Table 2 summarizes the demographic, clinical, and 

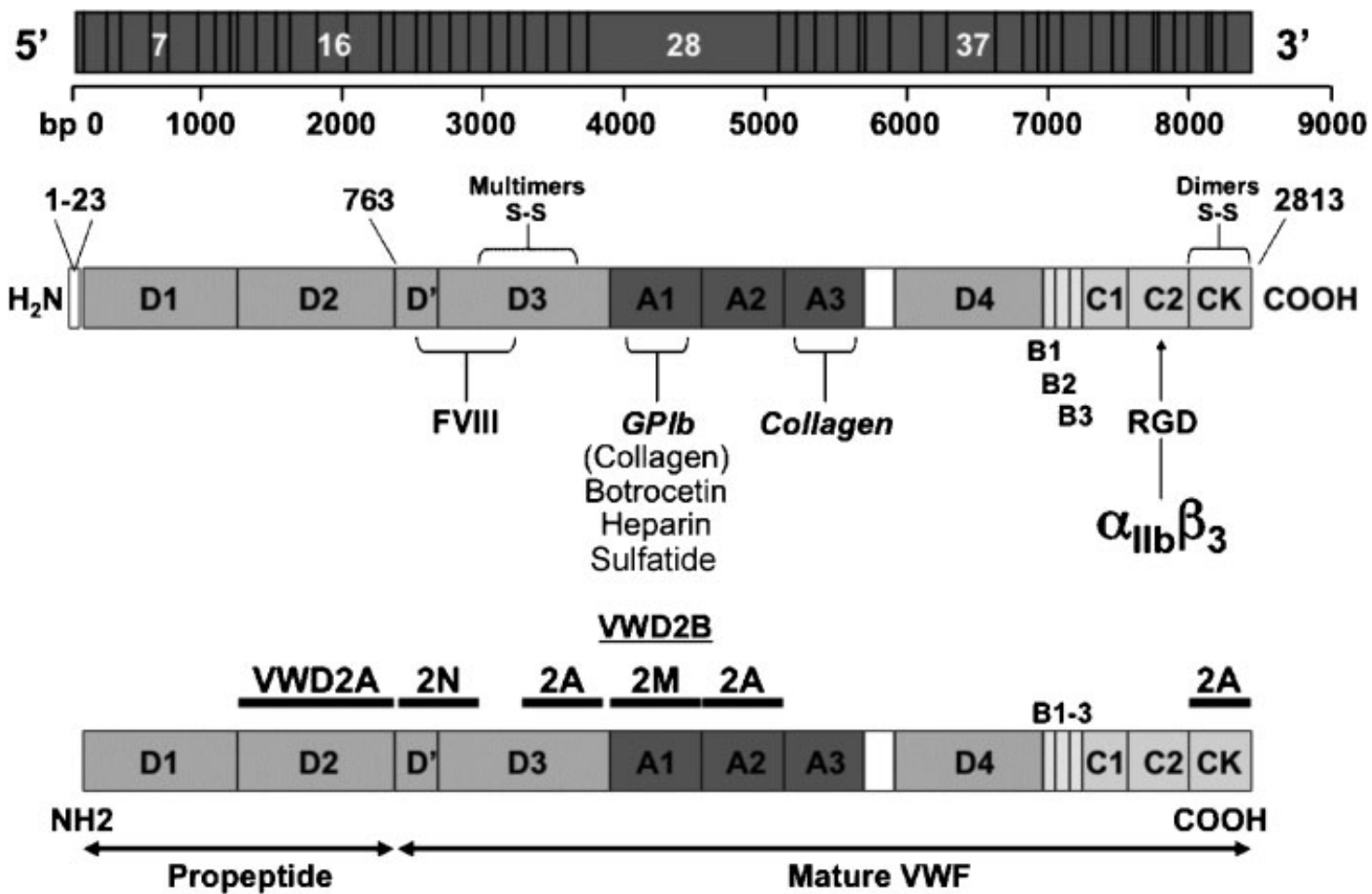

Figure 2 Schematic representation of the von Willebrand factor (VWF) gene located in chromosome 12: The main exons are indicated with the number of base pairs from $5^{\prime}$ to $3^{\prime}$ (upper panel). The structure of VWF functional domains: the pre-pro-VWF is indicated with amino acids numbered from the amino- (aa 1) to carboxy-terminal portions (aa 2813) of VWF. Note the important CK and D3 domains for formation of WWF dimers and multimers. The native mature subunit of VWF, after the cleaving of the pre-pro WWF, is described with its functional domains: the VWF binding sites for factor VIII (D' and D3), Glycoprotein (GP)lb, botrocetin, heparin, sulfatide, collagen (A1), collagen (A3), and the RGD sequence for binding to $\alpha$ llb $\beta 3$ (intermediate panel). Distribution of VWF mutations in patients with VWD2: the positions of mutations causing VWD2A, VWD2B, VWD2M, and VWD2N are indicated with black bars throughout the VWF domains (lower panel).

laboratory data of the 1234 cases included in RENAWI. VWD types could be identified (family $n$; \%) as follows: VWD1 $=779 \quad(279 ; \quad 63), \quad$ VWD2A $=87 \quad(31 ; 7)$, $\mathrm{VWD} 2 \mathrm{~B}=73 \quad(22 ; 6), \quad \mathrm{VWD} 2 \mathrm{M}=219 \quad(67 ; 18)$,
$\operatorname{VWD} 2 \mathrm{~N}=10(5 ; 1)$, and $\operatorname{VWD} 3=66(47 ; 5)$. Women were more frequently diagnosed among all VWD $(58 \%)$, especially in milder types (VWD1 $=60 \%$ ); they were equal to men in VWD2A (48\%), VWD2N (50\%), and

Table 2 Demographic, Clinical, and Laboratory Data [Median (Range)] of Patients Enrolled in RENAWI

\begin{tabular}{|c|c|c|c|c|c|c|c|}
\hline & VWD1 & VWD2A & VWD2B & VWD2M & VWD2N & VWD3 & All VWD \\
\hline No. of cases (\%) & 779 (63) & $87(7)$ & $73(6)$ & 219 (18) & $10(1)$ & $66(5)$ & $1234(100)$ \\
\hline No. of families & 279 & 31 & 22 & 67 & 5 & 47 & 451 \\
\hline $\begin{array}{l}\text { Gender M/F } \\
\text { (\% female) }\end{array}$ & $311 / 468(60)$ & $45 / 42(48)$ & $29 / 44(60)$ & $101 / 118(54)$ & $5 / 5(50)$ & $32 / 34(51)$ & $523 / 711(58)$ \\
\hline $\begin{array}{l}\text { Median age } \\
\text { (yr) (range) }\end{array}$ & $35(2-87)$ & $34(3-77)$ & $33(5-87)$ & $37(4-96)$ & $20(4-54)$ & $28(1-72)$ & $32(1-96)$ \\
\hline Bleeding time (min) & $7(2.5-35)$ & $21(6-35)$ & $14(4-35)$ & $10(3-35)$ & $7(5-13)$ & 35 (15-35) & $15(2.5-35)$ \\
\hline RIPA (mg/mL) & $1.30(1.1-3.5)$ & $2.00(1.4-3.5)$ & $0.60(0.3-0.8)$ & $1.60(1.3-3.5)$ & $1.1(1.1-1.2)$ & $3.5(0.3-3.5)$ & 1.50 \\
\hline WWF:RCo (U/dL) & $37(5-56)$ & $6(2-68)$ & $20(6-79)$ & $7(3-50)$ & $37(26-100)$ & $<3(<3-100)$ & 18 \\
\hline WWF:Ag (U/dL) & $40(5-60)$ & 36 6-140) & $48(16-180)$ & $24(3-120)$ & $33(26-98)$ & $<1(<1-180)$ & 28 \\
\hline WWF:RCo/Ag (ratio) & $0.92(0.6-1.6)$ & $0.23(0.1-0.6)$ & $0.46(0.1-1)$ & $0.50(0.1-0.6)$ & $1.0(0.9-1.3)$ & n.c. $(0.1-1.6)$ & 0.61 \\
\hline FVIII:C (U/dL) & $52(2-187)$ & $46(12-140)$ & $50(16-140)$ & $35(2-144)$ & $20(6-33)$ & $6(1-22)$ & $35(1-140)$ \\
\hline FVIII/NWF:Ag (ratio) & $1.65(0.8-2)$ & 1. $23(0.6-2)$ & $1.27(0.4-2)$ & $1.4(0.6-2)$ & $0.46(0.2-0.6)$ & n.c. $(0.2-2)$ & 1.28 \\
\hline
\end{tabular}

Bleeding time $>30$ minutes was calculated as $35 ; \mathrm{RIPA}>3 \mathrm{mg} / \mathrm{mL}$ was calculated as $3.5 ; \mathrm{VWF}: \mathrm{RCo}<3$ and $\mathrm{VWF}: \mathrm{Ag}<1 \mathrm{U} / \mathrm{dL}$ was considered as $1 \mathrm{U} / \mathrm{dL}$ to calculate ratios.

RENAWI, National Registry of von Willebrand Disease; VWD, von Willebrand disease; RIPA, ristocetin-induced platelet agglutination; VWF, von Willebrand factor; RCo, ristocetin cofactor; Ag, antigen; C, coagulant activity; nc, not calculated. 
VWD3 (51\%). Patients had a median age of 32 years, even though VWD2N (median: 20 years) and VWD3 (median: 28 years) cases were diagnosed at younger ages.

Despite the fact that the BT was not introduced among the tests recommended for VWD diagnosis, ${ }^{3,17}$ BT has been used extensively in VWD diagnosis, and it was prolonged in most cases (15 minutes) with a wide range from 2.5 to $>30$ minutes. Values of RIPA were always $>1.1 \mathrm{mg} / \mathrm{mL}$ in all VWD except for the 73 cases with VWD2B, and there were very heterogeneous according to the levels of the interactions of reduced or abnormal VWF with its platelet receptor. According to the enrollment criteria, the levels of VWF:RCo were always below the lower limit of normal individuals with non-O blood group in all VWD except for a few cases of VWD2A, VWD2B, and VWD2N; in VWD3, VWF:RCo was undetectable. Differently from VWF:RCo, the VWF:Ag levels were undetectable or reduced only in all VWD3 and VWD1, but they were reduced or normal in all the other VWD types. The ratio between VWF:RCo and VWF:Ag (VWF:RCo/Ag) could be always calculated in these VWD cases, thanks to the use of the most sensitive ELISAVWF:RCo performed when VWF:RCo levels were $<15 \mathrm{U} / \mathrm{dL}{ }^{14}{ }^{14}$ Therefore, the classification of VWD1 versus VWD2M based on VWF:RCo/Ag $>0.6$ or $<0.6$ could be obtained also in patients with very low levels of VWF:Ag.

FVIII levels were always reduced in VWD3 because of undetectable levels of VWF:Ag and in the case of VWD2N because of the defective VWF binding to FVIII (VWF:FVIIIB). As the last parameter used to characterize our VWD cohort, we calculated the ratios between FVIII and VWF:Ag and found that FVIII-toVWF:Ag was always $>1.2$ in all VWD except for VWD2N.

\section{Patients with Different Von Willebrand Disease Types and Bleeding Symptoms}

Table 3 shows the number (percentage) of patients with VWD types who had at least one episode among the 11 bleeding symptoms considered at the time of their inclusion in RENAWI. Mucosal bleedings such as epistaxis (57\%), menorrhagia (53\%), bleeding from minor wounds (38\%), and gum bleeding (32\%) were more frequently observed than hematomas (13\%) and joint bleeding (6\%). The percentages of symptoms are much higher in the most severe VWD types such as VWD3, VWD2A, and VWD2B, as shown by the very dramatic cerebral bleeding (VWD3) and gastrointestinal bleeding (VWD2A, VWD2B, and VWD3). However, the percentages of patients who experienced some mucosal bleedings such as epistaxis, menorrhagia, and gum bleeding do not differ significantly among VWD types. Conversely, hematomas and joint bleedings were more frequently observed in VWD2N and VWD3 patients characterized by relatively low levels of FVIII. Note that there were patients who did not show any symptoms at the time of the inclusion in RENAWI despite the lower levels of VWF activities measured in their plasma.

\section{Molecular Diagnosis of Patients with Von Willebrand Disease}

Molecular diagnosis was performed by two Italian laboratories on DNA available in at least one affected member of the 328 of 451 families (73\%) with VWD. Although all families with VWD2A, VWD2B, VWD2M, and VWD2N could be tested, DNA samples from only 168 of 279 VWD1 families (60\%) and 54 of 66 VWD3 families (82\%) were available for the analyses. Table 4 summarizes the most frequent molecular defects found in VWD patients. As far as VWD1, a relatively large cohort of patients $(n=108.9 \%)$ carried

Table 3 Number of Patients (\%) Who Showed One of the Different Bleeding Symptoms

\begin{tabular}{|c|c|c|c|c|c|c|c|}
\hline & VWD1 & VWD2A & VWD2B & VWD2M & VWD2N & VWD3 & All VWD \\
\hline No. of cases (\%) & $779(63)$ & $87(7)$ & $73(6)$ & $219(18)$ & $10(1)$ & $66(5)$ & $1234(100)$ \\
\hline Epistaxis & $412(53)$ & $61(70)$ & $49(67)$ & $123(56)$ & $4(40)$ & $\underline{51(77)}$ & $699(57)$ \\
\hline Menorrhagia* & $374(48)$ & $25(40)$ & $26(59)$ & $105(58)$ & $2(40)$ & $22(65)$ & $654(53)$ \\
\hline Postdental extraction & $327(42)$ & $37(43)$ & $27(37)$ & $92(42)$ & $3(30)$ & $27(41)$ & $456(37)$ \\
\hline Bleeding from minor wounds & $273(35)$ & $31(36)$ & $37(51)$ & $81(37)$ & $3(30)$ & $\underline{36(55)}$ & $469(38)$ \\
\hline Gum bleeding & $210(27)$ & $38(44)$ & $31(42)$ & $70(32)$ & $0(-)$ & $\underline{38(58)}$ & $394(32)$ \\
\hline Postsurgical bleeding & $280(36)$ & $42(48)$ & $35(48)$ & $\underline{98(45)}$ & $2(20)$ & $30(45)$ & $494(40)$ \\
\hline Gastrointestinal bleeding & $31(4)$ & $15(17)$ & $7(10)$ & $18(8)$ & $0(-)$ & $13(20)$ & $87(7)$ \\
\hline Hematomas & $93(12)$ & $12(14)$ & $12(16)$ & $13(6)$ & $4(40)$ & $31(47)$ & $161(13)$ \\
\hline Joint bleeding & $15(2)$ & 7 (8) & $12(16)$ & $13(6)$ & $1(10)$ & $27(41)$ & $78(6)$ \\
\hline Hematuria & $16(2)$ & $5(6)$ & $3(4)$ & $7(3)$ & $1(10)$ & $8(12)$ & $40(3)$ \\
\hline Cerebral bleeding & $5(0.6)$ & $2(2)$ & $0(-)$ & $1(0.6)$ & $0(-)$ & $6(9)$ & $14(1)$ \\
\hline
\end{tabular}

*Women only.

Underlined values indicate similar percentages among the noted VWF types.

WWD, von Willebrand disease. 
Table 4 List of the Most Frequent Mutations in Italian Von Willebrand Disease According to von Willebrand Factor Domains

\begin{tabular}{lll}
\hline Localization of VWF Defects & VWD Types & VWF Mutations Associated with Specific Types \\
\hline D'-D3 domains & VWD2N & R816W/Q; R854Q/W; R924Q; C1060R \\
D3 domain & VWD1 Vicenza & R1205H (M740I) \\
& VWD1 & C1130F/R \\
& VWD2A & C1143Y; C1173R \\
& (formerly IIE) & \\
A1 domain & VWD2B & P1266L/Q; H1268D; R13060/L/W; \\
& (formerly IIB) & R1308C/P; I1309V; V1316M \\
& VWD2M & R1337L; R13410/W \\
A2 domain & VWD2A & S1506L; S1543F; R1597W; V1607D \\
& (formerly IIA) & G1629R; G1631D; V1665E \\
& VWD1 & Y1584C \\
A3 domain & & \\
CK and other domains & VWD1 & A1716P; V1822G \\
& VWD1 & R2313H; C2362F; S2469P
\end{tabular}

* Note that in the case of patients with VWD3 and VWD1, additional molecular defects have been identified but could not be reported in this article because most of them are novel and currently under evaluation in expression studies in collaboration with other colleagues. The frequency of these mutations is described in the text.

VWF, von Willebrand factor: VWD, von Willebrand disease.

the mutation $\mathrm{R} 1205 \mathrm{H}$ with or without M740I typically observed in VWD1 "Vicenza." Among other frequent gene defects observed in the Italian VWD1, the following molecular abnormalities could be identified: small deletion or insertions (D1277/E78delinsE), missense (C1130F/R, A1716P, V1822G, R2318H, C2362F, S2469P), or nonsense (Q1475X, R1779X) mutations. In the DNA from the 54 of 66 VWD3 patients, the molecular abnormalities were heterogeneous $(\mathrm{pt}-\mathrm{n})$ : large deletion (7); small deletions and insertions (18); nonsense (9); and splice site (8) and missense (12) mutations. Note that the seven VWD3 patients characterized by large gene deletions had at least one episode of life-threatening anaphylactic reaction in their lifetime.

\section{DDAVP Trial and Clinical Use of DDAVP and/or VWF/FVIII Concentrates}

Information was also collected about previous exposures to DDAVP trial and to DDAVP or VWF/FVIII concentrates used to treat bleeding episodes. Data are summarized in Table 5. A DDAVP trial was performed in at least one affected member of VWD family as follows: VWD1 (74\%), VWD2A (70\%), VWD2M (72\%), and VWD2N (70\%). No patient with VWD3 and only a minority of VWD2B (41\%) cases were currently exposed to this trial. However, even though DDAVP trial showed a good rate of biological responses: VWD1, 69\%; VWD2A, 26\%; VWD2M,
33\%; and VWD2N, 71\%, not all these patients were treated with DDAVP to manage or prevent bleeding. For comparison, the percentages of patients with VWD1 (30\%), VWD2A (84\%), VWD2B (62\%), VWD2M (63\%), VWD2N (30\%), and VWD3 (91\%) who were exposed to VWF/FVIII concentrates with or without DDAVP are shown in Table 5. As far as the amount and frequency of the clinical use of these two main therapeutic agents, we could identify the number of VWD patients who were given DDAVP (more than five doses per year) and VWF/FVIII concentrates $(>50,000$ VWF:RCo IU/year). The frequency and the dosage of DDAVP as well as of VWF/FVIII concentrates have been reported to be very heterogeneous among the VWD types (Table 5). The percentages of VWD who received relatively large amount of DDAVP and or VWF/FVIII concentrates are relatively low, $11 \%$ and $19 \%$, respectively, of the total cohort of patients. Within this group of VWD treated more frequently, 11 patients were under secondary long-term prophylaxis as reported elsewhere. ${ }^{23}$ However, there were VWD patients who had never been exposed to bleeding and therefore also never been exposed to DDAVP and/or VWF/FVIII concentrates.

\section{DISCUSSION}

The data of this retrospective registry on Italian patients with inherited VWD (RENAWI) have been collected and analyzed for $>8$ years. Even though the first sets of 
Table 5 Patients in RENAWI Exposed to Desmopressin (DDAVP) Infusion Trial and to One or More Therapeutic Agents after Evaluation of DDAVP Biological Response

\begin{tabular}{|c|c|c|c|c|c|c|c|}
\hline & VWD1 & VWD2A & VWD2B & VWD2M & VWD2N & VWD3 & All VWD \\
\hline No. of cases (\%) & $779(63)$ & $87(7)$ & $73(6)$ & $219(26)$ & $10(1)$ & $66(5)$ & $1234(100)$ \\
\hline \multicolumn{8}{|l|}{$\begin{array}{l}\text { DDAVP trial and } \\
\text { biological responses: }\end{array}$} \\
\hline DDAVP trial (\%) & $576(74)$ & $61(70)$ & $30(41)$ & $158(72)$ & $7(70)$ & $5(7)$ & 837 (68) \\
\hline $\begin{array}{l}\text { Biological response } \\
\text { to DDAVP* }\end{array}$ & $397 / 576(69 \%)$ & $15 / 61(26 \%)$ & $6 / 30(20 \%)$ & $52 / 158(33 \%)$ & $5 / 7(71 \%)$ & $0 / 5(0 \%)$ & $467 / 837(56 \%)$ \\
\hline \multicolumn{8}{|l|}{$\begin{array}{l}\text { Clinical use of DDAVP } \\
\text { and/or VWF/FVIII } \\
\text { concentrates during } \\
\text { the previous } 12 \text { mo: }\end{array}$} \\
\hline DDAVP & $\begin{array}{l}270 / 779 \\
(35 \%)\end{array}$ & $\begin{array}{l}14 / 87 \\
(16 \%)\end{array}$ & $\begin{array}{l}10 / 73 \\
(14 \%)\end{array}$ & $\begin{array}{l}64 / 219 \\
(29 \%)\end{array}$ & $\begin{array}{l}4 / 10 \\
(40 \%)\end{array}$ & $\begin{array}{l}0 / 66 \\
(0 \%)\end{array}$ & $\begin{array}{l}376 / 1234 \\
(30 \%)\end{array}$ \\
\hline $\begin{array}{l}\text { Patients with } \\
>5 \text { doses/yr }\end{array}$ & 108/779 (14\%) & $5 / 87(6 \%)$ & $2 / 73(3 \%)$ & $15 / 219(7 \%)$ & $2 / 10(20 \%)$ & $0 / 66(0 \%)$ & $132 / 1234(11 \%)$ \\
\hline $\begin{array}{l}\text { VWF/FVIII } \\
\text { concentrates }\end{array}$ & $237 / 779(30 \%)$ & $73 / 87(84 \%)$ & $45 / 73(62 \%)$ & $138 / 219(63 \%)$ & $3 / 10(30 \%)$ & 60/66 (91\%) & $463 / 1234(36 \%)$ \\
\hline $\begin{array}{l}\text { Patients with } \\
>50,000 \mathrm{UI} / \mathrm{yr} \\
\text { (VWF:RCo) }\end{array}$ & $86 / 779$ (11\%) & $31 / 87(36 \%)$ & 23/73 (31\%) & $56 / 219(26 \%)$ & $1 / 10(10 \%)$ & $37 / 66(56 \%)$ & $234 / 1234(19 \%)$ \\
\hline
\end{tabular}

*The definition of biological response is described within the text.

RENAWI, National Registry of von Willebrand Disease; VWF, von Willebrand factor; F, factor.

results could be collected at the end of 2002, it took almost 4 years to complete the revision of phenotypic data of the first cohort of 1529 patients included as "bona fide" VWD according to local tests. Two laboratories expert on VWF assays retested those patients $(n=400)$ who showed borderline VWF levels in plasma using not only more standardized assays for VWF:RCo and VWF:Ag but also multimeric analyses and VWF:FVIIIB assays as recommended. ${ }^{3,17}$ After this reevaluation, 295 of 1529 (19\%) still did not meet criteria for VWD diagnosis and therefore were excluded from any further analyses. These findings confirmed that appropriate laboratory tests useful to make VWD diagnosis are not available in many Italian centers. This is especially true for molecular diagnosis because the 1234 patients could be characterized by gene defects during the last 3 years only in a few laboratories. Eventually, after such an extensive revision of phenotype and genotype, we could identify one of the largest cohorts of well-characterized patients useful to describe the current management of VWD in Italy.

In all the reviews about VWD published for the past 25 years, VWD1 has been considered the most frequent VWD $(>70 \%) \cdot{ }^{1-5} \mathrm{~A}$ frequency of $>70 \%$ in VWD1 was also reported previously by the two Italian publications of the AICE ${ }^{2,3}$ before the current analyses of RENAWI. The relatively lower percentage of VWD1 (63\%) in RENAWI is believed to be more correct because it is balanced by the relative larger number of VWD2M patients (18\%) who could be diagnosed ac- cording to the more appropriate criteria used in the current analyses. Indeed, the VWF: $\mathrm{RCo} / \mathrm{Ag}$ ratio using the most sensitive ELISA-VWF:RCo was critical in the differential diagnosis between VWD1 and VWD2M in all patients including also those VWD with VWF:RCo levels $<15 \mathrm{U} / \mathrm{dL} .{ }^{14}$ Such a relatively lower percentage of VWD1 because of misdiagnosed VWD2M or VWD2A has been also shown previously by other authors. ${ }^{24,25}$ Some authors could report lower percentages of VWD1 using the VWF:RCo/Ag ratios and genotypes; ${ }^{24}$ others could identify higher percentages of VWD2A or VWD2M by using sensitive multimeric analyses and genotypes. ${ }^{25}$ In agreement with these reports, we could identify all the VWD types of RENAWI more appropriately using VWF:RCo/Ag ratios, multimeric analyses, and genotypes.

Several authors proposed the use of collagenbinding activity of VWF (VWF:CB) with VWF:CBto $-\mathrm{Ag}$ ratios in the differential diagnosis between VWD1 and VWD2A or VWD2M. ${ }^{26-28}$ This approach can be useful sometimes, but unfortunately, VWF:CB was available in Italy only in a few centers, and therefore only a minority of cases could be tested with this assay (data not shown). VWD2B was identified mainly by $\mathrm{RIPA}$, independently from the VWF: $\mathrm{RCo} / \mathrm{Ag}$ ratio and multimeric analyses, as discussed recently; ${ }^{29}$ differential VWD2A or VWD2M diagnoses always required multimeric analyses in the presence of $\mathrm{VWF}: \mathrm{RCo} / \mathrm{Ag}<0.6$.

All VWD2N showed low levels of FVIII with a FVIII/VWF-to-Ag ratio $<1$, but these were confirmed 
by the specific VWF:FVIIIB assay. The frequency of VWD2N patients in the RENAWI is apparently lower than that reported by the current literature. ${ }^{1,4-6} \mathrm{How}^{-}$ ever, we could have missed additional patients with VWD2N because the specific VWF:FVIIIB assay was not performed in all VWD. Patients with VWD3 showed undetectable levels of VWF:Ag and very reduced levels of FVIII. Seven patients from three different families developed anti-VWF inhibitors with life-threatening reactions in their lifetime. ${ }^{30-32}$ The assay for VWF propeptide was available in only two centers and was used only in a few patients, especially in those with VWD1 "Vicenza" (data not shown). Despite the fact that BT was not recommended by the AICE, this assay is still in use in most Italian centers; the PFA100 is currently used in only a few centers (data not shown).

The number of patients who showed different bleeding symptoms was analyzed according to the most recent classification of VWD types within RENAWI, and therefore the percentages are different from those shown in our previous reports. ${ }^{2,3}$ Nevertheless, we confirm that mucosal bleedings such as epistaxis, menorrhagia, bleeding from minor wounds, gum bleeding) were more frequently observed than hematomas (13\%) and joint bleeding (6\%). Unfortunately, we could report only the type of symptoms without the semiquantitative evaluation of bleeding severity because we could not apply at the time of the study the questionnaire used to calculate the BS. ${ }^{16}$ This semiquantitative evaluation of bleeding symptoms has so far been used for the prospective study organized within the same cohort of patients, but only on 797 of 1234 patients (65\%) (data not shown).

Molecular diagnosis was performed in most of the affected members with VWD types, and the results obtained were useful to determine family groups with specific genotype. For instance, we could find a very high frequency of the mutation $\mathrm{R} 1205 \mathrm{H}$ with or without M740I typically observed in VWD1 "Vicenza" in 108 of 1234 patients (9\%). ${ }^{33,34}$ Among other mutations found in this cohort of patients, the most frequently (more than five families) observed are the following: C1130F/R，R1306Q/L/W，R1308C/P，R1315C/L, $\mathrm{R} 1374 \mathrm{C} / \mathrm{H}, \mathrm{R} 1597 \mathrm{~W}$, and $\mathrm{Y} 1584 \mathrm{C}$. In the case of VWD3 patients, the molecular abnormalities were heterogeneous: It is important to identify that all seven patients with a large deletion of the VWF gene showed the presence of anti-VWF inhibitors and showed lifethreatening anaphylactic reactions ${ }^{31,32}$. However, larger prospective studies should be organized to determine predictors of bleeding and of anti-VWF inhibitors in VWD3. ${ }^{35}$

As far as the treatment of Italian VWD, the results of RENAWI showed that DDAVP was regularly assessed as part of the diagnostic workup in most VWD patients. All the hematologists were aware of the standardized protocol and could evaluate correctly the biological response after a DDAVP trial according to previous recommendations. ${ }^{18,19}$ Nevertheless, even though a DDAVP trial showed a relatively high rate of biological response, not all these patients were treated with DDAVP to manage or prevent bleeding. This apparent contradiction is currently under evaluation in a multicenter prospective clinical trial on the use of DDAVP in $>200$ VWD patients. ${ }^{36}$

Compared with patients with hemophilia, VWD patients are certainly less exposed to severe bleeding, and therefore it is not surprising that only a small percentage of VWD cases usually are treated with VWF/FVIII concentrates following spontaneous and/or trauma-induced bleeds. Nevertheless, even thought there are VWD patients who bleed only rarely and therefore use DDAVP or VWF/FVIII concentrates usually only to prevent bleeding during surgery, there is a group of VWD cases in RENAWI who are regularly treated. These patient not only receive large amounts of VWF:FVIII concentrates, but also a few of them are currently under secondary long-term prophylaxis because of recurrent bleedings at the same sites: gastrointestinal bleeding (VWD1, VWD2A, VWD2M) and hemarthrosis (VWD3). ${ }^{23}$ Therefore data from RENAWI were also useful to make an estimate on the current use of DDAVP and VWF/FVIII concentrates per year in Italian VWD as requested by the Italian Ministry of Health. The predictors of bleeds in patients with VWD and the need for DDAVP and VWF/FVIII concentrates are currently under evaluation in another prospective study. ${ }^{35,36}$ Even though it was not a specific aim of RENAWI, the Italian patients with VWD previously exposed to plasma-derived VWF/FVIII concentrates have been also evaluated for their incidence of bloodborne infections. Thanks to the use of DDAVP since 1977 and of a pasteurized VWF/FVIII concentrate since 1984, the incidence of hepatitis $\mathrm{C}$ virus infection is relatively low. ${ }^{37}$

In conclusion, the information gathered in RENAWI from one of the largest cohorts of well-characterized VWD patients has been extremely useful to better understand the current management of Italian patients and can be compared with data obtained from other countries. Despite many attempts to improve the diagnostic workup of VWD, appropriate phenotypic and genotypic tests are not available in most hemophilia centers: Only a few laboratories could perform the correct identification and classification of VWD type. This suggests that evidence-based studies should be performed only in well-characterized patients tested by laboratories expert in the clinical, laboratory, and molecular markers of VWD: These studies should aim at evaluating the predictors of bleeding according to these markers. The clinical use of DDAVP $>30$ years after its 
introduction in Italy was certainly less frequent than expected from the data of biological response. Only the results of another large prospective study can provide the reasons of these discrepant findings. Last but not least, the VWF/FVIII concentrates used in Italy have been effective and safe in most patients with VWD who have been treated with them to stop bleeding, to prevent bleeding during major/minor surgeries, and also in a few cases in secondary longterm prophylaxis.

\section{ACKNOWLEDGMENTS}

This retrospective study was organized with grants from the Italian Ministry of Health to ABF and PMM. The colleagues who could include RENAWI in $>100$ cases of VWD are listed as coauthors. PB, EO, and AI were responsible for the analytical and epidemiological evaluation of the data received by the coordinators (ABF, PMM). MTC and LB worked on the confirmation of phenotypic and genotypic parameters at the coordinating center. We wish to thank all the colleagues who participated in RENAWI by including patients in the database online or helping in the evaluation of laboratory data in the different locations (cities) of the hemophilia centers: F. Baudo, F. Stabile, G. Mostarda, M. Genini, A. Lattuada, R. Bader, I. Forza, G. Cozzi (Milan); G. Gamba (Pavia); A. Scaraggi (Bari); F. Muleo (Catanzaro); G. Rossetti (Trento); G. Rodorigo (Bologna); M. Turello (Udine); G. Gandini (Verona); A.R. Tagliaferri (Parma); R. Musso (Catania).

\section{REFERENCES}

1. Sadler JE, Budde U, Eikenboom JC, et al; Working Party on von Willebrand Disease Classification. Update on the pathophysiology and classification of von Willebrand disease: a report of the Subcommittee on von Willebrand factor. J Thromb Haemost 2006;4(10):2103-2114

2. Federici AB, Mannucci PM. Management of inherited von Willebrand disease in 2007. Ann Med 2007;39(5):346-358

3. Federici AB, Castaman G, Mannucci PM. Guidelines for the diagnosis and management of VWD in Italy. Haemophilia 2002;8:607-621

4. Pasi KJ, Collins PW, Keeling DM, et al. Management of von Willebrand disease: a guideline from the UK Haemophilia Centre Doctors' Organization. Haemophilia 2004;10(3): 218-231

5. Nichols WL, Hultin MB, James AH, et al. von Willebrand disease (VWD): evidence-based diagnosis and management guidelines, the National Heart, Lung, and Blood Institute (NHLBI) Expert Panel report (USA). Haemophilia 2008; 14(2):171-232

6. Mannucci PM, Franchini M, Castaman G, Federici AB; Italian Association of Hemophilia Centers. Evidence-based recommendations on the treatment of von Willebrand disease in Italy. Blood Transfus 2009;7(2):117-126
7. Tosetto A, Castaman G, Rodeghiero F. Evidence-based diagnosis of type 1 von Willebrand disease: a Bayes theorem approach. Blood 2008;111(8):3998-4003

8. Rodeghiero F, Castaman G, Dini E. Epidemiological investigation of the prevalence of von Willebrand's disease. Blood 1987;69(2):454-459

9. Goodeve A, Eikenboom J, Castaman G, et al. Phenotype and genotype of a cohort of families historically diagnosed with type 1 von Willebrand disease in the European study, Molecular and Clinical Markers for the Diagnosis and Management of Type 1 von Willebrand Disease (MCMDM1VWD). Blood 2007;109(1):112-121

10. James PD, Notley C, Hegadorn C, et al. The mutational spectrum of type 1 von Willebrand disease: results from a Canadian cohort study. Blood 2007;109(1):145-154

11. Barbui T, Baudo F, Ciavarella N, et al; Italian Working Group. Spectrum of von Willebrand's disease: a study of 100 cases. Br J Haematol 1977;35(1):101-112

12. Mannucci PM, Ruggeri ZM, Pareti FI, Capitanio A. 1-Deamino-8-d-arginine vasopressin: a new pharmacological approach to the management of haemophilia and von Willebrands' diseases. Lancet 1977;1(8017):869-872

13. Iorio A, Oliovecchio E, Morfini M, Mannucci PM; Association of Italian Hemophilia Centres Directors. Italian Registry of Haemophilia and Allied Disorders. Objectives, methodology and data analysis. Haemophilia 2008;14(3): 444-453

14. Federici AB, Canciani MT, Forza I, et al. A sensitive ristocetin co-factor activity assay with recombinant glycoprotein Ibalpha for the diagnosis of patients with low von Willebrand factor levels. Haematologica 2004;89(1):77-85

15. Baronciani L, Cozzi G, Canciani MT, et al. Molecular characterization of a multiethnic group of 21 patients with type 3 von Willebrand disease. Thromb Haemost 2000; 84(4):536-540

16. Tosetto A, Rodeghiero F, Castaman G, et al. A quantitative analysis of bleeding symptoms in type 1 von Willebrand disease: results from a multicenter European study (MCMDM-1 VWD). J Thromb Haemost 2006;4(4): 766-773

17. Federici AB, Canciani MT. Clinical and laboratory versus molecular markers for a correct classification of von Willebrand disease. Haematologica 2009;94(5):610-615

18. Federici AB, Mazurier C, Berntorp E, et al. Biologic response to desmopressin in patients with severe type 1 and type 2 von Willebrand disease: results of a multicenter European study. Blood 2004;103(6):2032-2038

19. Castaman G, Lethagen S, Federici $A B$, et al. Response to desmopressin is influenced by the genotype and phenotype in type 1 von Willebrand disease (VWD): results from the European Study MCMDM-1VWD. Blood 2008;111(7): 3531-3539

20. Federici AB, Baudo F, Caracciolo C, et al. Clinical efficacy of highly purified, doubly virus-inactivated factor VIII/von Willebrand factor concentrate (Fanhdi) in the treatment of von Willebrand disease: a retrospective clinical study. Haemophilia 2002;8(6):761-767

21. Federici AB, Castaman G, Franchini M, et al. Clinical use of Haemate $\mathrm{P}$ in inherited von Willebrand's disease: a cohort study on 100 Italian patients. Haematologica 2007;92(7): 944-951

22. Federici AB, Barillari G, Zanon E, et al. Efficacy and safety of highly purified, doubly virus-inactivated VWF/FVIII 
concentrates in inherited von Willebrand's disease: results of an Italian cohort study on 120 patients characterized by bleeding severity score. Haemophilia 2010;16(1):101-110

23. Federici AB. Highly purified VWF/FVIII concentrates in the treatment and prophylaxis of von Willebrand disease: the PRO. WILL Study. Haemophilia 2007;13(Suppl 5): $15-24$

24. Nitu-Whalley IC, Riddell A, Lee CA, et al. Identification of type 2 von Willebrand disease in previously diagnosed type 1 patients: a reappraisal using phenotypes, genotypes and molecular modelling. Thromb Haemost 2000;84(6): 998-1004

25. Schneppenheim R, Budde U. Phenotypic and genotypic diagnosis of von Willebrand disease: a 2004 update. Semin Hematol 2005;42(1):15-28

26. Favaloro EJ. Collagen binding assay for von Willebrand factor (VWF:CBA): detection of von Willebrands disease (VWD), and discrimination of VWD subtypes, depends on collagen source. Thromb Haemost 2000;83(1): 127-135

27. Federici AB, Canciani MT, Forza I, Cozzi G. Ristocetin cofactor and collagen binding activities normalized to antigen levels for a rapid diagnosis of type 2 von Willebrand diseasesingle center comparison of four different assays. Thromb Haemost 2000;84(6):1127-1128

28. Favaloro EJ. Evaluation of commercial von Willebrand factor collagen binding assays to assist the discrimination of types 1 and 2 von Willebrand disease. Thromb Haemost 2010; 104(5):1009-1021

29. Federici AB, Mannucci PM, Castaman G, et al. Clinical and molecular predictors of thrombocytopenia and risk of bleeding in patients with von Willebrand disease type 2B: a cohort study of 67 patients. Blood 2009;113(3): $526-534$
30. Shelton-Inloes BB, Chehab FF, Mannucci PM, Federici AB, Sadler JE. Gene deletions correlate with the development of alloantibodies in von Willebrand disease. J Clin Invest 1987; 79(5):1459-1465

31. Mannucci PM, Tamaro G, Narchi G, et al. Life-threatening reaction to factor VIII concentrate in a patient with severe von Willebrand disease and alloantibodies to von Willebrand factor. Eur J Haematol 1987;39(5):467-470

32. Bergamaschini L, Mannucci PM, Federici AB, Coppola R, Guzzoni S, Agostoni A. Posttransfusion anaphylactic reactions in a patient with severe von Willebrand disease: role of complement and alloantibodies to von Willebrand factor. J Lab Clin Med 1995;125(3):348-355

33. Schneppenheim R, Federici AB, Budde U, et al. Von Willebrand disease type 2M "Vicenza" in Italian and German patients: identification of the first candidate mutation (G3864A; R1205H) in 8 families. Thromb Haemost 2000; 83(1):136-140

34. Castaman G, Missiaglia E, Federici AB, Schneppenheim R, Rodeghiero F. An additional unique candidate mutation (G2470A; M740I) in the original families with von Willebrand disease type $2 \mathrm{M}$ Vicenza and the G3864A (R1205H) mutation. Thromb Haemost 2000;84(2):350-351

35. Federici AB. Clinical and molecular markers of inherited von Willebrand disease type 3: are deletions of the VWF gene associated with alloantibodies to VWF? J Thromb Haemost 2008;6(10):1726-1728

36. Federici AB. The use of desmopressin in von Willebrand disease: the experience of the first 30 years (1977-2007). Haemophilia 2008;14(Suppl 1):5-14

37. Federici AB, Santagostino E, Rumi MG, et al. The natural history of hepatitis $\mathrm{C}$ virus infection in Italian patients with von Willebrand's disease: a cohort study. Haematologica 2006;91(4):503-508 